ISSN = 1980-993X - doi:10.4136/1980-993X
www.agro.unitau.br/ambi-agua
E-mail: ambi-agua@agro.unitau.br
Tel.: (12) 3625-4116

\title{
Principais usos da água do rio Sanhauá na área de influência do antigo lixão do Roger: proposta de revisão de enquadramento do rio
}

(doi:10.4136/ambi-agua.67)

\author{
Gilson Barbosa Athayde Júnior'; Claudia Coutinho Nóbrega²; Carmem Lúcia \\ Moreira Gadelha ${ }^{3}$; Natalia Cibely Bezerra Santana ${ }^{4}$; Magdalena Duarte Costa ${ }^{5}$
}

Departamento de Engenharia Civil e Ambiental, Centro de Tecnologia, Universidade Federal da Paraíba, Bairro Castelo Branco, João Pessoa-PB, Cep: 58.059-900

E-mail: ${ }^{1}$ gilson@ct.ufpb.br; ${ }^{2}$ claudiacn@uol.com.br; ${ }^{3}$ carmemgadelha@yahoo.com.br

${ }^{4}$ Bolsista de Iniciação Científica CNPq/UFPB

E-mail: natalianet@msn.com

${ }^{5}$ Mestranda em Engenharia Urbana pela Universidade Federal da Paraíba. Bolsista CT-Hidro - CNPq

E-mail: magdalenadcosta@yahoo.com.br

\section{RESUMO}

Verificaram-se os principais usos das águas do rio Sanhauá nas proximidades do antigo lixão do Roger, em João Pessoa. As visitas ao local foram realizadas em março, agosto e novembro de 2006 e fevereiro, maio e agosto de 2007. Foram identificadas atividades, como pesca, exploração de crustáceos e mariscos, navegação, recreação de contato primário, lançamento de esgoto, disposição de resíduos sólidos e dispersão do chorume gerado no antigo lixão. Dos entrevistados, 50,2\% declararam que utilizam o rio Sanhauá para pesca ou coleta de mariscos ou captura de crustáceos, $45,8 \%$ responderam que utilizam o rio para recreação de contato primário, contato secundário ou navegação, 93,1\% dos entrevistados responderam que o seu domicílio não é atendido por serviço público de esgotamento sanitário e com isso o destino final dos esgotos é o rio Sanhauá, e 46,6\% declararam que têm conhecimento de disposição de resíduos sólidos no rio, apesar de 100\% dos domicílios serem atendidos por serviço de coleta de lixo. Segundo esses usos, a Resolução CONAMA N ${ }^{\circ}$ 357/2005 e a salinidade da água, o enquadramento do rio Sanhauá seria de água salobra classe 1, mas atualmente ele é enquadrado na classe 3 de água doce. O monitoramento da qualidade da água mostrou que os padrões de qualidade estão em desacordo com a classe 1 para águas salobras, fazendo-se necessário por parte do poder público a adoção de medidas no sentido de compatibilizar os usos existentes com a qualidade da água do rio ou a revisão do enquadramento do corpo aquático.

Palavras-chave: usos da água; rio Sanhauá; antigo lixão do Roger, João Pessoa.

\section{Main usages of Sanhauá river water in the area of influence of the former Roger's open dump: revising proposal of its classification}

\section{ABSTRACT}

The main usages of surface water near to the former Roger's open dump were investigated by means of visits every three months. These visits were performed in: March 2006, August 2006, November 2006, February 2007, May 2007 and August 2007. The following activities were identified: fishing, crustacean and shellfish catchments, primary contact bath, discharge of sewage, disposal of solid wastes, and discharge of leachate generated by the former open dump. Furthermore, social-economical questionnaires were 
applied to the people living nearby. Results showed that $50.2 \%$ of interviewed people stated that uses the Sanhauá river water for fishing or crustacean or shellfish catchments; $45.8 \%$ said that use the river for primary or secondary contact bath or navigation; $93.1 \%$ of interviewed people said that their houses were not attended with sewage and so that, the final disposal site for the sewage was the Sanhauá river. Although all houses are attended by solid waste collection services, $46.6 \%$ of the interviewed people declared to know about solid wastes disposal at the Sanhauá river. According to these usages and CONAMA Resolution 357/2005 and the water salinity, the Sanhauá river would be classified into class 1 for brackish water, as opposed to its present classification: class 3. The monitoring showed that water quality standards were not in accordance to the class 1 for brackish water. Therefore, the environmental institution should adopt measures so that the water quality of Sanhauá river would be maintained or proceed to the revision for the river classification.

Keywords: water usages; Sanhauá river; Roger’s open dump.

\section{INTRODUÇÃO}

A importância da água reside no fato de ela ser essencial ao ser humano, ao desenvolvimento econômico e à preservação do meio ambiente. No que se refere ao ser humano, estima-se que, para atender às suas necessidades fisiológicas, uma pessoa precise de 2 a 3 litros de água por dia, embora o consumo per capita mínimo necessário para manter uma boa saúde seja da ordem de 100 L/dia. Essa quantidade de água supre, além das necessidades fisiológicas, outros usos, como higiene e preparação de alimentos. A saúde pública é igualmente dependente do acesso à água de boa qualidade, já que as doenças relacionadas com a água atingem no mundo mais de 1 bilhão de pessoas por ano, levando à morte, aproximadamente, 3 milhões. Esses números poderiam ser facilmente reduzidos se a população tivesse acesso a um serviço de saneamento adequado. No que se refere aos aspectos econômicos, a água serve de insumo para várias atividades, destacando-se a geração de energia, agricultura irrigada, abastecimento público e produção industrial. No Brasil, por exemplo, as usinas hidrelétricas são responsáveis por mais de $90 \%$ da energia gerada no país. Inúmeros processos industriais/agrícolas necessitam direto ou indiretamente de água para a sua realização. Além disso, o meio ambiente também é extremamente dependente e vulnerável a alterações das condições hidrológicas. A água possui um papel importante na manutenção dos ecossistemas, como por exemplo, os costeiros e os pântanos, que são particularmente vulneráveis, pois alterações hidrológicas podem levar a catástrofes ambientais irrecuperáveis (Vasconcelos et al, , 2008).

Apesar das fontes de água serem abundantes ao redor do planeta, são mal distribuídas. No Brasil, que possui grande disponibilidade de recursos hídricos, esse fato é bastante evidente, visto que a maior porcentagem (68,5\%) desses recursos está concentrada na região Norte onde habitam 7,6\% da população brasileira, enquanto que as regiões de maiores índices populacionais concentram poucos recursos hídricos: apenas 6\% no Sudeste e pouco mais de $3 \%$ no Nordeste, para uma população de 42,6\% e 28,1\%, respectivamente (Dias, 2007).

Além de mal distribuídas, atualmente as águas vêm sendo poluídas num ritmo bastante intenso. Poluição das águas pode ser definida como qualquer adição de matéria ou energia que altere as características naturais das águas de modo a limitar os usos previstos para ela (Brasil, 1981). A poluição da água pode indicar que um ou mais de seus usos preestabelecidos foram prejudicados. No Brasil, as águas doces, salobras e salinas são classificadas em trezes

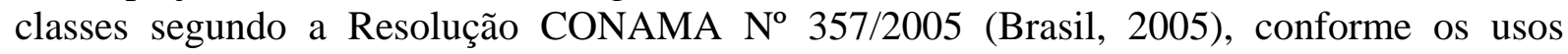
preponderantes destas. A partir disso, os parâmetros de qualidade da água são definidos para 
cada uma dessas classes, que devem ser seguidos para garantir a compatibilidade entre o uso e a qualidade. É importante atentar para o fato de que o enquadramento dos corpos de água deve estar baseado não necessariamente no seu estado atual, mas nos níveis de qualidade que deveriam possuir para atender aos padrões de qualidade da água da classe a que pertencem.

Dentre as diversas fontes possíveis de poluição hídrica, encontram-se os lixões, que apesar de serem uma forma inadequada de disposição final de resíduos sólidos, continuam sendo áreas para simples descarga do lixo sobre o solo, sem medidas de proteção ao meio ambiente ou à saúde pública. Segundo a pesquisa de saneamento básico do Instituto Brasileiro de Geografia e Estatística - IBGE (IBGE, 2000), 30,5\% dos resíduos sólidos produzidos no Brasil são destinados a lixões, enquanto que esse percentual para aterros controlados e aterros sanitários é de 22,3\% e 47,1\%, respectivamente.

O antigo lixão do Roger localizado na região Metropolitana de João Pessoa possui uma área de 17 ha e funcionou como depósito a céu aberto por mais de 40 anos, quando na verdade deveria ter uma vida útil de apenas 3 anos. Com o fechamento, pelo Ministério Público, dos lixões de Bayeux e Cabedelo, o antigo lixão do Roger passou a receber também o lixo proveniente dessas cidades, chegando a totalizar em média 900 toneladas/dia de resíduos domicialiares, hospitalares e entulhos (EMLUR, 2003). O antigo lixão do Roger está assentado no manguezal às margens do rio Sanhauá, um dos mais importantes do estado da Paraíba.

Apesar de ter sido desativado em 5 de agosto de 2003, o antigo lixão do Roger tem gerado grandes problemas de poluição e degradação dos cursos de água, na área do manguezal e na porção estuarina do rio Sanhauá, principalmente nas suas proximidades. $\mathrm{O}$ antigo lixão do Roger causa diversos efeitos negativos sobre o meio ambiente, principalmente devido à percolação do chorume, que pode ser definido (Segato e Da Silva, 2000; Martínez e Soto, 2000; Russo et al, 2000; Pessin et al, , 2000) como um líquido escuro altamente poluidor gerado pela degradação dos resíduos presentes no lixo. Ele é originado da umidade natural do lixo (aumentando no período chuvoso), da água de constituição da matéria orgânica que escorre durante o processo de decomposição e das bactérias existentes no lixo que expelem enzimas dissolvendo a matéria orgânica com formação de líquido. O chorume infiltra-se no solo, contaminando as águas subterrâneas e pelo escoamento superficial polui as águas superficiais. Assim, quando os resíduos sólidos não têm destinação adequada se transformam numa grande ameaça não somente para o meio ambiente como também para saúde pública, principalmente para a população que vive nas proximidades, que no caso do antigo lixão do Roger, pode-se citar a comunidade do Porto do Capim e da Favela do "S".

Nesse contexto, o objetivo do presente trabalho é caracterizar os principais usos da águas superficiais e manguezais na área de influência do antigo lixão do Roger, visando orientar medidas e ações por parte do poder público e órgãos ambientais, de maneira a minimizar os conflitos existentes, assegurar os padrões de qualidade da água e revisar o enquadramento do rio Sanhauá.

\subsection{Usos da água}

Os usos da água podem ser separados em grandes grupos (Bassoi e Guazelli, 2004): abastecimento público e industrial, irrigação e a dessedentação de animais, preservação da fauna e da flora aquática, recreação, geração de energia elétrica, navegação, diluição e transporte de efluentes. Desses usos listados, pode-se dizer que são consuntivos: o abastecimento humano e industrial, irrigação e dessedentação de animais, enquanto que recreação, conservação da flora e fauna, geração de energia elétrica, navegação, transporte de efluentes são não consuntivos.

O abastecimento doméstico é considerado o uso mais nobre associado aos recursos hídricos, visto que requer diversos critérios de qualidade da água. Além disso, o uso 
doméstico é a categoria mais homogênea, apresentando pequena variabilidade de consumo. A água destinada para o abastecimento doméstico é utilizada na área interna e externa da habitação. Engloba o consumo da água para beber, para fins alimentares e para higiene pessoal, sendo utilizada também para lavagem de roupas e de utensílios domésticos, irrigação de jardins, lavagem de veículos e limpeza em geral.

O abastecimento público engloba a utilização da água para irrigação de parques e jardins, lavagem de ruas e passeios, edificações e sanitários de uso público, fontes ornamentais, piscinas públicas, combate a incêndios, limpeza de coletores de esgotos, etc. Já o abastecimento comercial e industrial são os mais heterogêneos, ocorrendo desde pequenos consumidores de água como bares, padarias e pequenas indústrias artesanais, até grandes consumidores de água como shopping center e indústrias de bebida. A água de uso industrial é utilizada pela indústria nos processos de fabricação de seus produtos, como lavagem das matérias-primas e de equipamentos, usada também na alimentação de caldeiras e processos industriais em geral.

A irrigação é a atividade humana que mais utiliza água: $70 \%$ do consumo global (Shiklomanov, 1999). A qualidade da água usada para a irrigação varia em função dos tipos de culturas em que será aplicada, se alimentícias ou não.

Quanto à recreação, esse uso destina-se a atividades de dois tipos: contato primário, que tem imersão do corpo na água, e contato secundário que não tem imersão do corpo. A qualidade da água, principalmente nas atividades de contato direto com a água (contato primário), está baseada na presença de microorganismos patogênicos que transmitem doenças, colocando em risco a saúde humana.

A geração de energia elétrica utiliza o recurso hídrico de maneira a não modificar a qualidade da água captada, entretanto altera o ambiente e a vida aquática gerando conflitos entre os outros usos.

A preservação da fauna e da flora está relacionada com a qualidade da água, portanto os parâmetros utilizados na classificação das águas em seus usos preestabelecidos devem ter valores rígidos para garantir a vida aquática, incluindo os peixes, as aves e outros animais.

Diluição e transporte de efluentes: trata-se do uso menos nobre das águas, entretanto um dos mais utilizados pelo homem. A maior parte da água para consumo humano vem dos rios e é neles que são lançados os efluentes de natureza doméstica e/ou industrial, prejudicando o uso das águas receptoras. É preciso atentar para a importância do tratamento dos efluentes e de como são dispostos no meio ambiente, visto que alteram a qualidade da água tornando-a imprópria para outros fins.

Alguns desses usos provocam alterações na qualidade da água, podendo prejudicar o próprio uso gerador do conflito ou outros de maior importância. Na irrigação, por exemplo, parte da água utilizada não retorna ao corpo de água original e a parte que retorna tem qualidade inferior à captada (uso consuntivo), podendo torná-la imprópria para outros usos. Na recreação, por sua vez, ao modificar as características da água, esse uso prejudica o abastecimento humano.

\subsection{Monitoramento da qualidade da água como subsídio ao gerenciamento dos Recursos Hídricos}

Segundo Ward (1999, apud Soares e Lisot, 2007), um sistema de monitoramento ou sistema de informações de qualidade da água consiste de amostragem (localização dos pontos de coleta, escolha das variáveis, determinação da freqüência e tipo de amostragem estatística), análise laboratorial, manuseio de dados, preparação de relatórios e utilização dos dados obtidos para efeito de tomada de decisão.

Para realizar o monitoramento de um corpo aquático, utiliza-se a análise de parâmetros físicos, químicos e biológicos, tais como: $\mathrm{pH}$, turbidez, sólidos (totais, dissolvidos), cor, 
condutividade elétrica, OD, DBO, DQO, nitrato, nitrito, fósforo total, chumbo, cloretos, alumínio, coliformes (totais e termotolerantes).

\subsection{Enquadramento dos corpos aquáticos}

Conforme a Política Nacional de Recursos Hídricos, (Brasil, 1997), o enquadramento dos corpos hídricos em classes, segundo os usos preponderantes da água, visa assegurar às águas qualidade compatível com os usos mais exigentes a que forem destinadas e diminuir os custos de combate à poluição das águas, mediante ações preventivas permanentes.

De acordo com a Resolução CNRH No 12/2000 (Brasil, 2000a), os procedimentos para o enquadramento de corpos aquáticos em classes segundo os usos preponderantes deverão ser desenvolvidos observando as seguintes etapas:

I - diagnóstico do uso e da ocupação do solo e dos recursos hídricos na bacia hidrográfica;

II - prognóstico do uso e da ocupação do solo e dos recursos hídricos na bacia hidrográfica;

III - elaboração da proposta de enquadramento; e

IV - aprovação da proposta de enquadramento e respectivos atos jurídicos.

Na etapa de diagnóstico serão abordados os seguintes itens:

I - caracterização geral da bacia;

II - aspectos jurídicos e institucionais;

III - aspectos socioeconômicos;

IV - uso e ocupação atual do solo;

V - identificação das áreas reguladas por legislação específica e das áreas em processo de degradação;

VI - usos, disponibilidade e demanda atual de águas superficiais e subterrâneas;

VII - identificação das fontes de poluição pontuais e difusas atuais oriundas de efluentes domésticos e industriais, de atividades agropecuárias e de outras fontes causadoras de degradação ambiental sobre os recursos hídricos; e

VIII - estado atual dos corpos hídricos, apresentando a condição de qualidade por trecho, consubstanciado por estudos de autodepuração.

Na etapa de prognóstico serão formuladas projeções com horizontes de curto, médio e longo prazos, objetivando o desenvolvimento sustentável, que incluirão:

I - evolução da distribuição das populações e das atividades econômicas;

II - evolução de usos e ocupação do solo;

III - políticas e projetos de desenvolvimento existentes e previstos;

IV - evolução da disponibilidade e da demanda de água;

V - evolução das cargas poluidoras dos setores urbano, industrial, agropecuário e de outras fontes causadoras de degradação ambiental dos recursos hídricos;

VI - evolução das condições de quantidade e qualidade dos corpos hídricos, consubstanciada em estudos de simulação; e

VII - usos desejados de recursos hídricos em relação às características específicas de cada bacia.

Na etapa de elaboração da proposta de enquadramento serão desenvolvidas, para cada projeção, alternativas de enquadramento: uma de referência e uma ou mais prospectivas, todas com base nas informações obtidas e nas avaliações feitas nas etapas de diagnóstico e prognóstico.

$\mathrm{Na}$ etapa de aprovação da proposta de enquadramento e respectivos atos jurídicos deverão ser observados os procedimentos previstos na Resolução CNRH Nº12/2000 e 
segundo essa mesma Resolução o enquadramento dos corpos aquáticos em classes deve obedecer às normas estabelecidas na legislação ambiental específica.

No Brasil, a Resolução CONAMA No 357/2005 (Brasil, 2005), dispõe sobre a classificação dos corpos de água e diretrizes ambientais para o seu enquadramento. As águas do território nacional foram divididas em águas doces (salinidade $<0,5 \%$ ), salobras (salinidade entre 0,5\% e 30\%o) e salinas (salinidade > 30\%o). Em função da qualidade requerida para os seus usos preponderantes, foram criadas 13 classes de qualidade.

A classificação das águas salobras é:

I - Classe especial: águas destinadas: integral;

a) à preservação dos ambientes aquáticos em unidades de conservação de proteção

b) à preservação do equilíbrio natural das comunidades aquáticas.

II - Classe 1: águas que podem ser destinadas:

a) à recreação de contato primário, conforme Resolução CONAMA N² 274/2000 (Brasil, 2000b);

b) à proteção das comunidades aquáticas;

c) à aqüicultura e à atividade de pesca;

d) ao abastecimento para consumo humano após tratamento convencional ou avançado;

e) à irrigação.

III - Classe 2 : águas que podem ser destinadas:

a) à pesca amadora;

b) à recreação de contato secundário.

IV - Classe 3: águas que podem ser destinadas:

a) à navegação;

b) à harmonia paisagística.

Os padrões de qualidade das águas determinados na Resolução CONAMA Nº 357/2005, no seu Capítulo III, estabelecem limites individuais para cada substância em cada classe.

\section{MATERIAIS E MÉTODOS}

Para caracterizar os principais usos da água do rio Sanhauá (João Pessoa, PB) foi feito um monitoramento trimestral pelo levantamento de dados in situ em visitas à área de influência direta e também indireta do antigo lixão do Roger, compreendendo toda a porção estuarina do rio Sanhauá até sua confluência com o rio Paraíba do Norte. O antigo lixão do Roger se localiza na porção oeste de João Pessoa, adjacente ao manguezal às margens do rio Sanhauá (e Paraíba do Norte), conforme ilustrado na Figura 1. As visitas ao local foram realizadas em março, agosto e novembro de 2006 e fevereiro, maio e agosto de 2007. Os dados foram obtidos por meio da aplicação de questionário socioambiental (Tabela 1) aos moradores das comunidades do Porto do Capim e da favela do "S", ambas localizadas nas proximidades do lixão. 
ATHAYDE JÚNIOR, G. B.; NÓBREGA, C. C.; GADELHA, C. L. M.; SANTANA, N. C. B.; COSTA, M. D. Principais usos da água do rio Sanhauá na área de influência do antigo lixão do Roger: proposta de revisão de enquadramento do rio. Ambi-Agua, Taubaté, v. 3, n. 3, p. 128-142, 2008. (doi:10.4136/ambi-agua.67)

Tabela 1. Questionário aplicado à população do Porto do Capim e Favela do "S".

\begin{tabular}{|c|c|c|c|c|}
\hline & \multirow[b]{2}{*}{ QUESTIONÁRIO } & \multicolumn{3}{|c|}{ Resultados (\%) } \\
\hline & & Sim & Não & $\begin{array}{c}\text { Não } \\
\text { soube/não } \\
\text { quis opinar }\end{array}$ \\
\hline 1 & $\begin{array}{l}\text { Você tem conhecimento de despejo de resíduos sólidos no rio Sanhauá no } \\
\text { entorno do porto do capim? }\end{array}$ & & & \\
\hline 2 & $\begin{array}{l}\text { Você tem conhecimento da existência de poços no entorno do antigo lixão do } \\
\text { Roger? }\end{array}$ & & & \\
\hline 3 & A água do rio Sanhauá é utilizada para abastecimento em seu domicílio? & & & \\
\hline 4 & $\begin{array}{l}\text { Alguém residente de seu domicílio utiliza o rio Sanhauá para pesca ou coleta } \\
\text { de mariscos ou captura de crustáceos? }\end{array}$ & & & \\
\hline 5 & $\begin{array}{l}\text { Alguém residente de seu domicílio utiliza o rio Sanhauá para recreação de } \\
\text { contato primário, contato secundário ou navegação? }\end{array}$ & & & \\
\hline 6 & Seu domicílio é atendido por serviço de abastecimento de água? & & & \\
\hline 7 & Seu domicílio é atendido por serviço publico de esgotamento sanitário? & & & \\
\hline 8 & Seu domicílio é atendido por serviço de coleta de resíduos sólidos? & & & \\
\hline 9 & $\begin{array}{l}\text { Você concorda com a forma com a qual o rio Sanhauá vem sendo tratado pelo } \\
\text { poder público? }\end{array}$ & & & \\
\hline 10 & $\begin{array}{l}\text { O rio Sanhauá no entorno do Porto do Capim, é utilizado para harmonia } \\
\text { paisagística? }\end{array}$ & & & \\
\hline 11 & $\begin{array}{l}\text { Você concorda com a forma com a qual o rio Sanhauá vem sendo tratado pela } \\
\text { população? }\end{array}$ & & & \\
\hline 12 & Há quanto tempo reside neste domicílio? $\quad$ Média & & & \\
\hline 13 & Quantas pessoas residem em seu domicílio? Média & & & \\
\hline 14 & Qual a renda familiar em seu domicílio? & & & \\
\hline 15 & Qual a máxima escolaridade em seu domicílio? & & & \\
\hline
\end{tabular}

Além da aplicação dos questionários foram feitos registros fotográficos de atividades (usos da água e manguezal) e para analisar a qualidade da água do Rio Sanhauá foram realizadas coletas pontuais de amostras de águas superficiais em quatro pontos localizados nas proximidades do antigo lixão do Roger. Tais pontos, denominados P1, P2, P3 e P4, são mostrados na Figura 1 e suas coordenadas geográficas são mostradas na Tabela 2.

Os parâmetros analisados foram: oxigênio dissolvido (OD), alumínio, chumbo, coliformes termotolerantes, nitrato e cloretos. As análises físico-químicas e microbiológicas seguiram as recomendações da APHA (1998).

Das etapas estabelecidas pela Resolução CNRH N¹2/2000 já descritas anteriormente para os procedimentos de enquadramento de corpos aquáticos segundo os usos preponderantes foi realizada nesse trabalho a etapa de diagnóstico envolvendo os seguintes itens: usos; identificação das fontes de poluição pontuais e difusas atuais oriundas de efluentes domésticos e industriais, de atividades agropecuárias e de outras fontes causadoras de degradação ambiental; e estado atual do corpo hídrico, apresentando a condição de qualidade por trecho. 


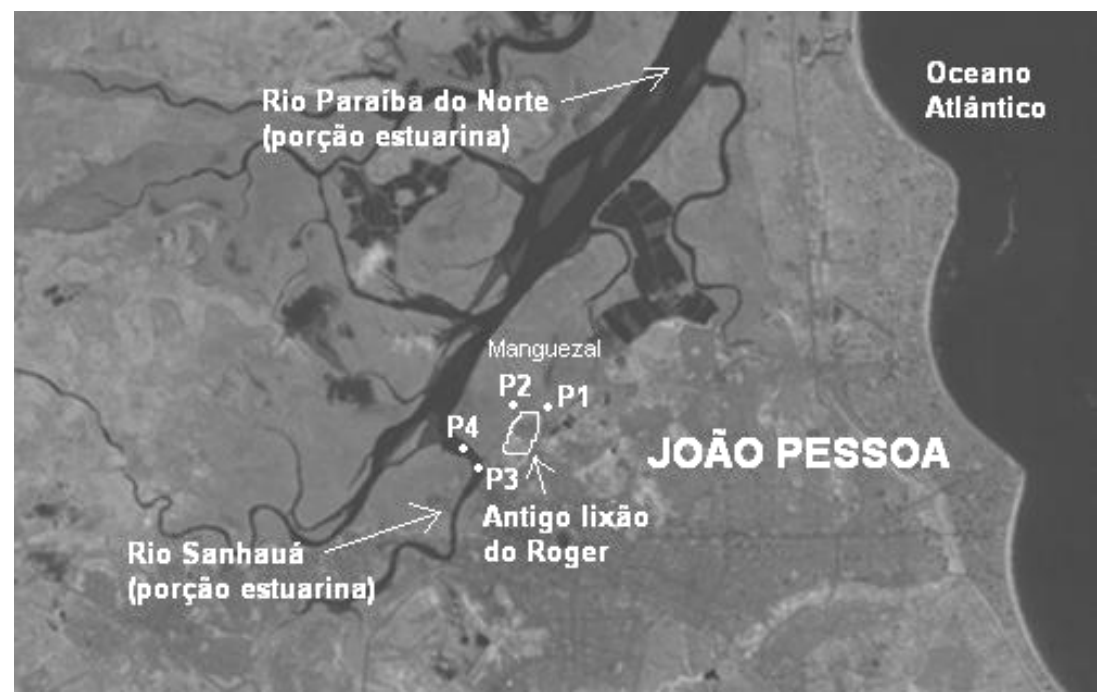

Figura 1. Localização da área de estudo e dos pontos P1, P2, P3 e P4. Fonte: INTERSAT (2001).

Tabela 2. Localização geográfica dos pontos de coleta.

\begin{tabular}{c|c|c|c}
\hline \multirow{2}{*}{ Ponto } & \multicolumn{2}{|c|}{ Coordenadas UTM } & \multicolumn{2}{c}{ Descrição } \\
\cline { 2 - 3 } & $\mathbf{E}$ & $\mathbf{N}$ & \\
\hline P1 & 292072 & 9214178 & Córrego afluente e sob influência de maré do rio Sanhauá \\
\hline P2 & 291629 & 9214276 & Córrego afluente e sob influência de maré do rio Sanhauá \\
\hline P3 & 291154 & 9213558 & Rio Sanhauá, à montante do antigo lixão do Roger \\
\hline P4 & 291141 & 9213774 & Rio Sanhauá, à jusante do antigo lixão do Roger \\
\hline
\end{tabular}

\section{RESULTADOS E DISCUSSÃO}

\subsection{Usos preponderantes da água do rio Sanhauá nas proximidades do antigo lixão do Roger}

Em relação à recreação de contato primário, contato secundário ou navegação observa-se que um percentual situado na faixa de 40-55\% (Figura 2) dos entrevistados faz uso das águas para essas atividades não consuntivas, o percentual médio foi de 45,8\%. Nas visitas realizadas na área de influência do antigo lixão do Roger verificou-se, principalmente, crianças tomando banho no rio, e uso de embarcações não motorizadas.

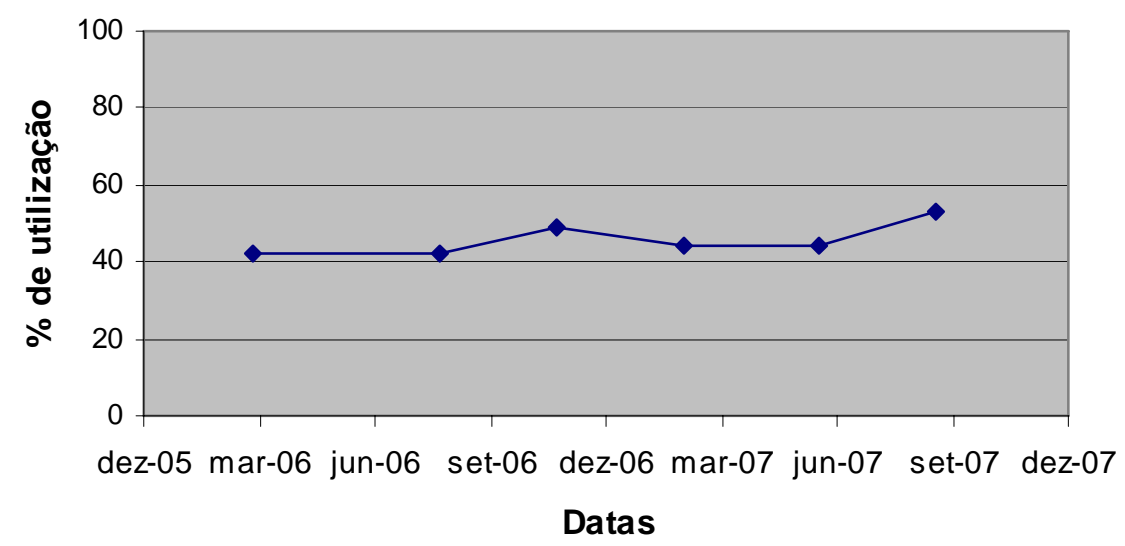

Figura 2. Utilização do rio Sanhauá para recreação de contato primário, contato secundário ou navegação. 
De acordo com a Figura 3, constata-se um percentual de utilização das águas do rio Sanhauá variando na faixa 20-70\% para pesca ou coleta de mariscos ou captura de crustáceos. O percentual médio para esses usos foi de 50,2\%.

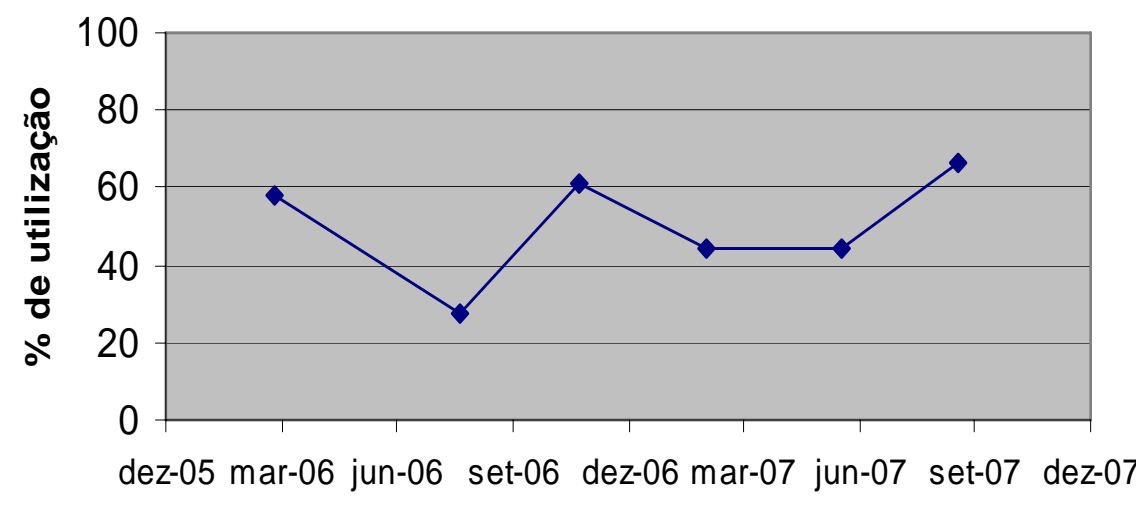

Datas

Figura 3. Utilização do rio Sanhauá para pesca ou coleta de mariscos ou captura de crustáceos.

Em média, 93,12\% dos entrevistados responderam que o seu domicílio não é atendido por serviço público de esgotamento sanitário (Figura 4) e com isso o destino final dos esgotos é o rio Sanhauá, ocorrendo de forma direta ou indireta através de galeria de água pluvial, causando prejuízos aos outros usos da água.

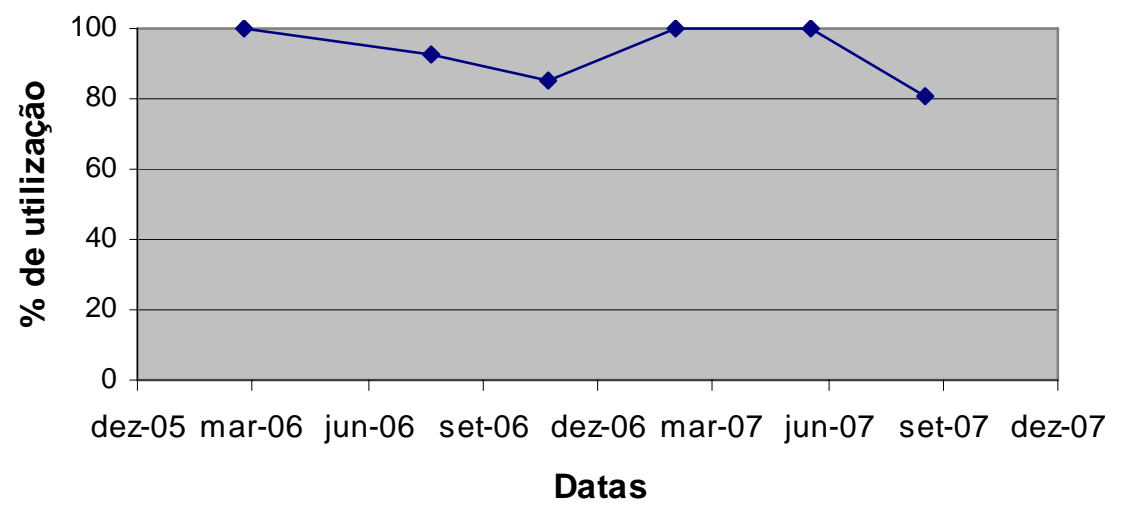

Figura 4. Lançamento de esgoto doméstico no rio Sanhauá (para as localidades estudadas).

Com base nos questionários aplicados aos moradores do Porto do Capim, da favela do "S" e do entorno do antigo lixão do Roger, observa-se que mesmo essas áreas sendo atendidas por serviço de coleta de resíduos sólidos ainda existem pessoas que fazem uso do rio Sanhauá para despejo de lixo, provocando conflitos e indisponibilizando a água para outras finalidades. Na Figura 5, pode-se perceber que um percentual variando entre 20 e $60 \%$ dos entrevistados declararam ter conhecimento de despejo de resíduos sólidos no rio Sanhauá. 


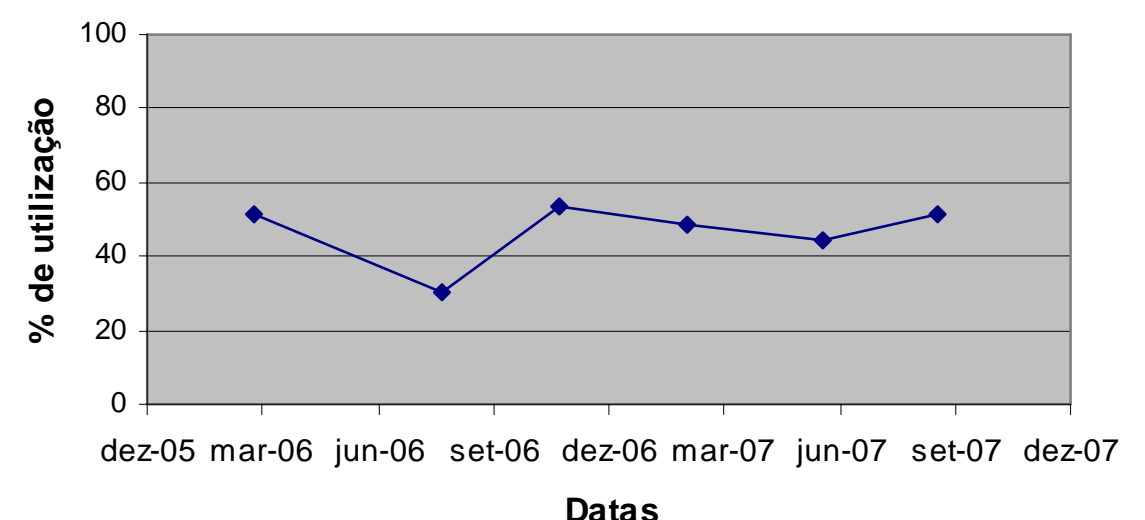

Figura 5. Conhecimento de despejo de resíduos sólidos.

De acordo com a Figura 6 constata-se que nas primeiras campanhas realizadas, nenhum dos entrevistados respondeu que utiliza a água do rio Sanhauá para uso no domicílio, entretanto na última inspeção uma pequena parcela das pessoas entrevistadas $(2,13 \%)$ respondeu que faz uso doméstico da água do Rio Sanhauá.

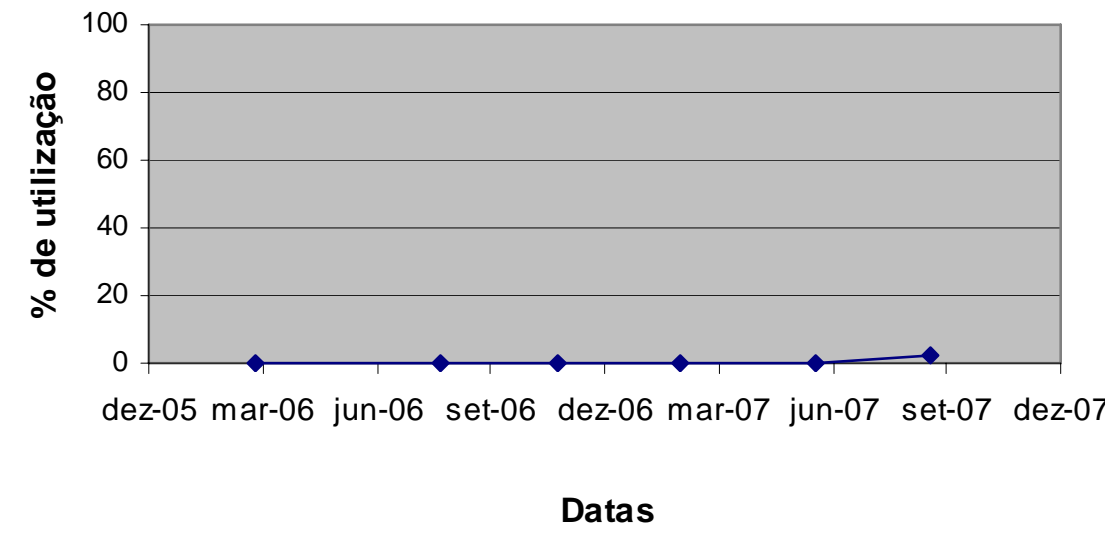

Figura 6. Utilização do rio Sanhauá para uso no domicílio.

\subsection{Monitoramento da qualidade da água no rio Sanhauá}

De acordo com a Superintendência de Administração do Meio Ambiente do Estado da Paraíba (SUDEMA, 1988), o rio Sanhauá está classificado como Classe 3 (água doce), baseando-se na antiga Resolução CONAMA No 20/1986 (Brasil, 1986). Entretanto, segundo essa última Resolução, bem como na Resolução CONAMA No 357/2005, que alterou a anterior, águas com salinidade igual ou inferior a 0,5\%o são consideradas como água doce e águas com salinidade entre $0,5 \%$ e $30 \%$ como água salobra. De acordo com as amostras de água superficial coletadas nos pontos P1, P2, P3 e P4, verificou-se que esses pontos apresentaram valores de cloretos nesta última faixa (Figura 12). Verificou-se, também, a presença de manguezais no rio, ecossistemas estes que são característicos de águas salobras, não ocorrendo o aparecimento deles em águas doces e, além do fato de o rio situar-se numa área que sofre influência da maré (região estuarina). Portanto as águas do rio Sanhauá no trecho considerado são salobras e não doces.

Segundo a Resolução CONAMA N $357 / 2005$ e os usos preponderantes da água verificados no rio Sanhauá (recreação, navegação, pesca, captura e coleta de mariscos ou crustáceos, lançamento de esgoto doméstico, despejos de resíduos sólidos), percebe-se que as águas deste se enquadrariam na Classe 1 de água salobra. 
A seguir são apresentados os resultados das análises físico-químicas e microbiológicas realizadas nas amostras de água superficial, coletadas num córrego no manguezal afluente ao rio Sanhauá (pontos P1 e P2) e no próprio rio Sanhauá (pontos P3 e P4), além do correspondente valor máximo permitido (VMP) pela resolução CONAMA No 357/2005 para água salobra classe 1 (no caso do oxigênio dissolvido VMP é o valor mínimo permitido).

Observa-se que em quase todas as inspeções realizadas os pontos de coleta apresentaram valores de OD abaixo de $5 \mathrm{mg} / \mathrm{L}$ (Figura 7), estando, portanto em desacordo com o padrão de qualidade da água da Resolução CONAMA Nº 357/2005 para água salobra de Classe 1.

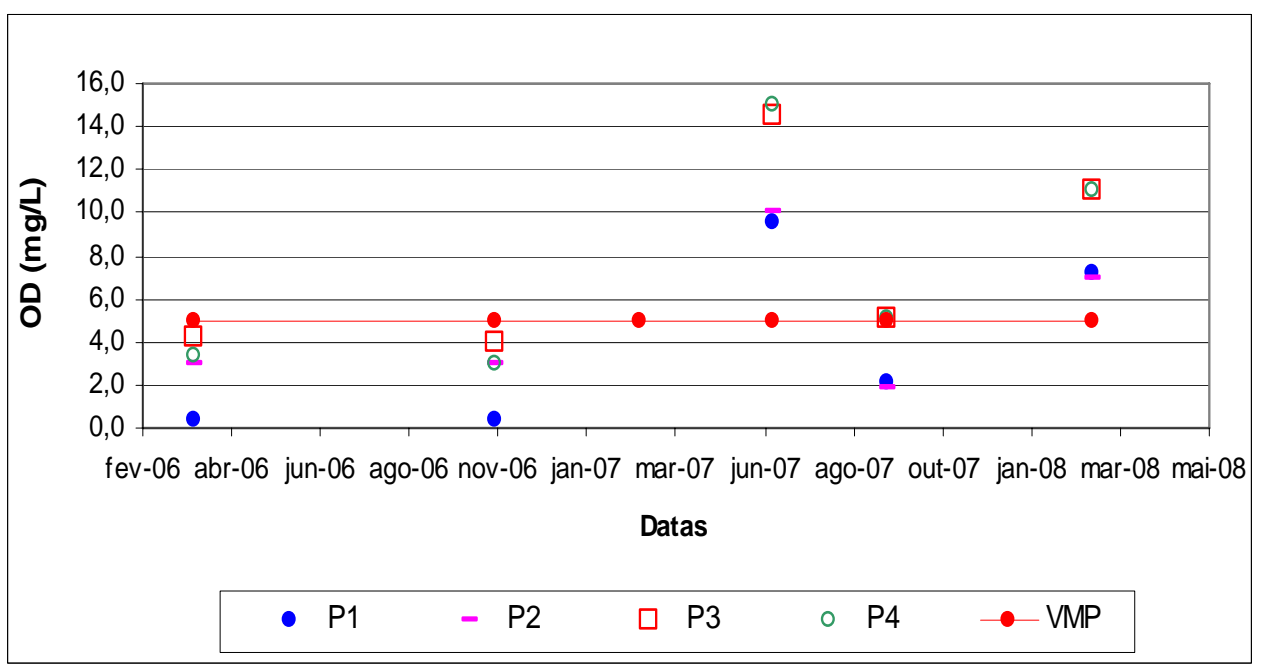

Figura 7. Variação temporal de OD (mg/L).

Segundo a Resolução CONAMA No 357/2005, o valor máximo permissível do parâmetro alumínio para água salobra de classe 1 é de $0,1 \mathrm{mg} / \mathrm{L}$, mas de acordo com a Figura 8, os valores para este parâmetro estiveram acima desse valor.

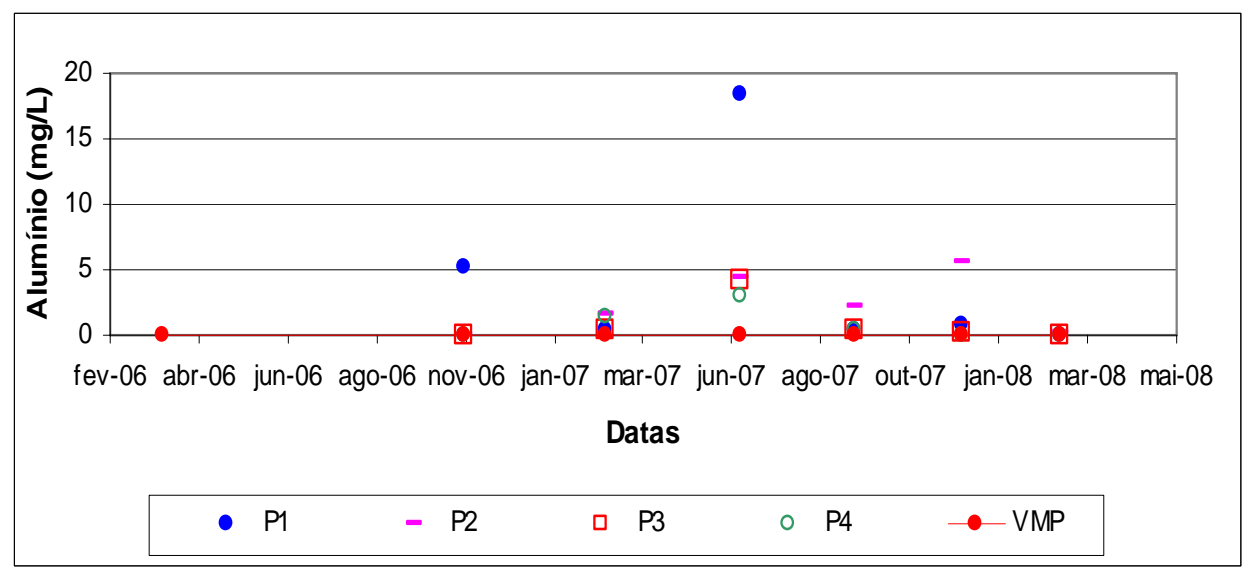

Figura 8. Variação temporal de Alumínio (mg/L).

Em relação à concentração de chumbo, verifica-se (Figura 9) que em todos os pontos prevalecem valores superiores ao valor máximo permissível da Resolução citada (0,01 mg/L). 
ATHAYDE JÚNIOR, G. B.; NÓBREGA, C. C.; GADELHA, C. L. M.; SANTANA, N. C. B.; COSTA, M. D. Principais usos da água do rio Sanhauá na área de influência do antigo lixão do Roger: proposta de revisão de enquadramento do rio. Ambi-Agua, Taubaté, v. 3, n. 3, p. 128-142, 2008. (doi:10.4136/ambi-agua.67)

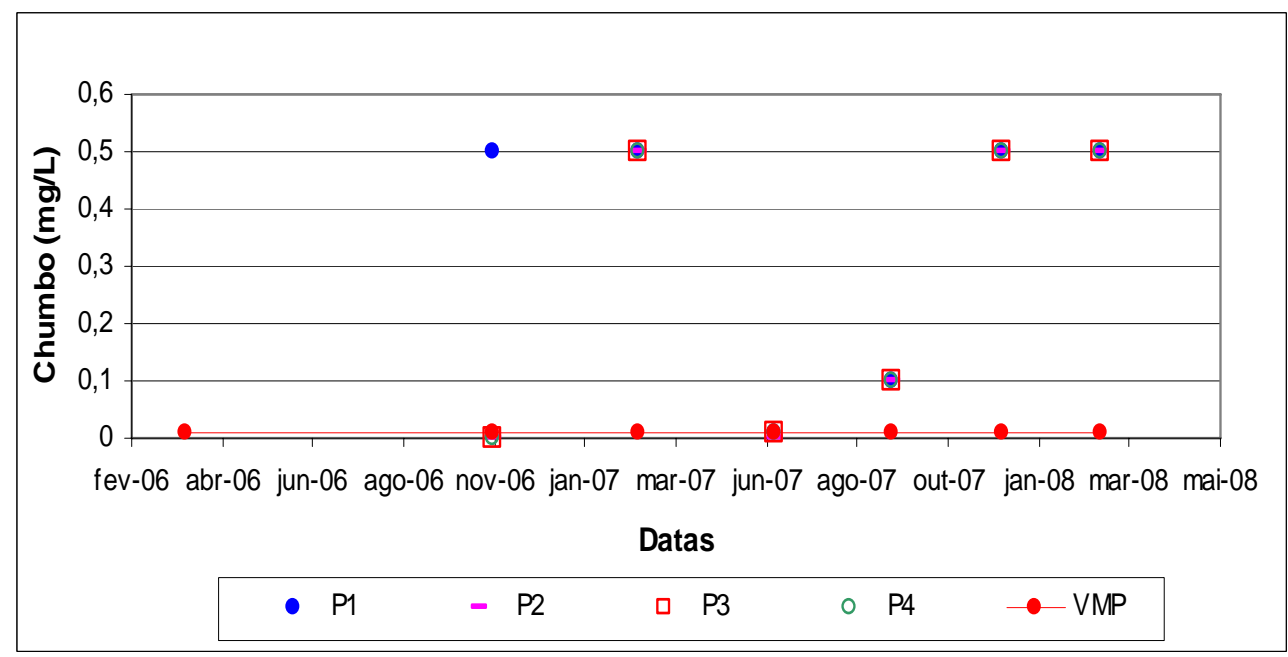

Figura 9. Variação temporal de Chumbo (mg/L).

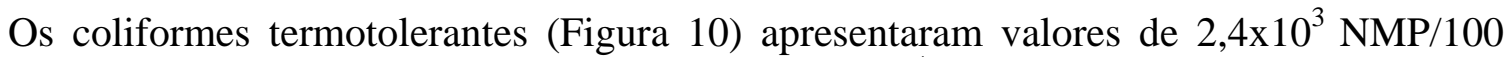
$\mathrm{mL}$, com exceção do ponto P1 na terceira coleta $\left(2,3 \times 10^{4} \mathrm{NMP} / 100 \mathrm{~mL}\right)$ e do ponto P2 na última coleta $\left(4,6 \times 10^{2} \mathrm{NMP} / 100 \mathrm{~mL}\right)$, e, portanto, estando em desacordo com os padrões de qualidade da água estabelecidos para águas salobras classe 1.

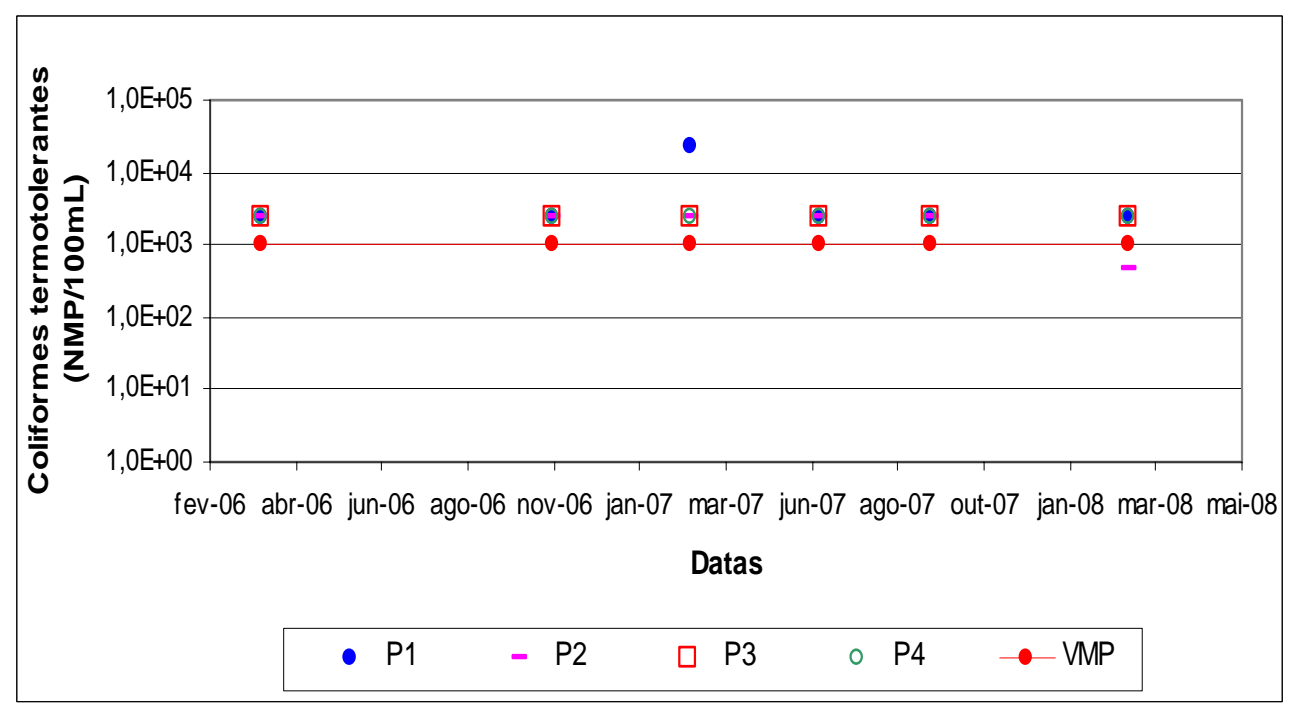

Figura 10. Variação temporal de Coliformes termotolerantes (NMP/100 ml).

Em relação ao parâmetro nitrato, observa-se que (Figura 11) na terceira campanha de coleta apenas o ponto P2 apresentou valor acima de $0,40 \mathrm{mg} / \mathrm{L}$ (VMP) e na quarta campanha todos os pontos apresentaram valores superiores ao valor máximo permissível.

Observa-se ainda que em todas as campanhas realizadas e em todos os pontos os valores de cloretos estiveram entre 5000 e 25000 mg/L (Figura 12). 


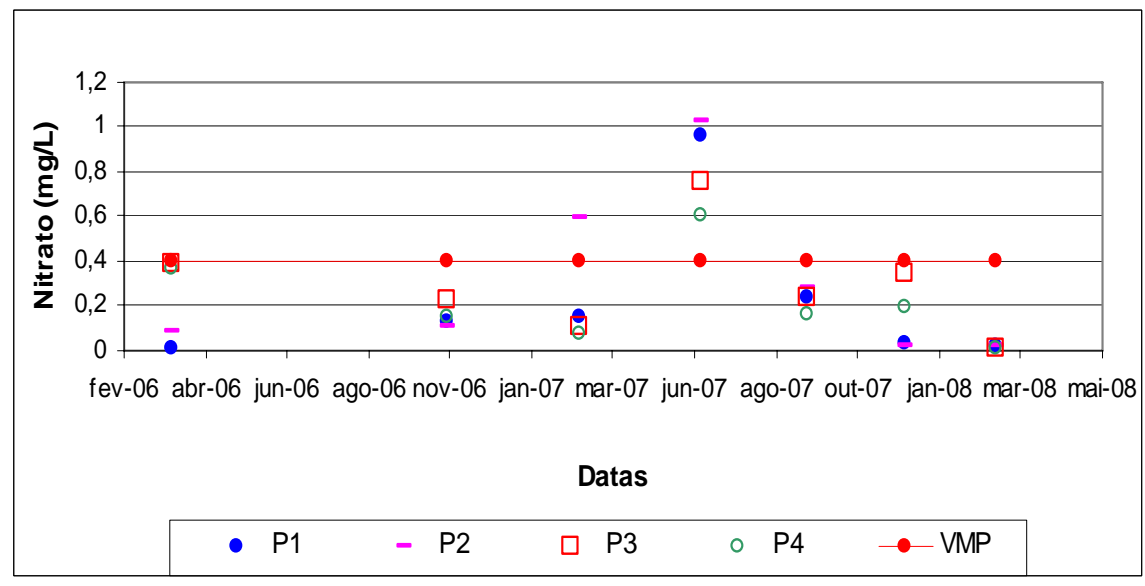

Figura 11. Variação temporal de Nitrato (mg/L).

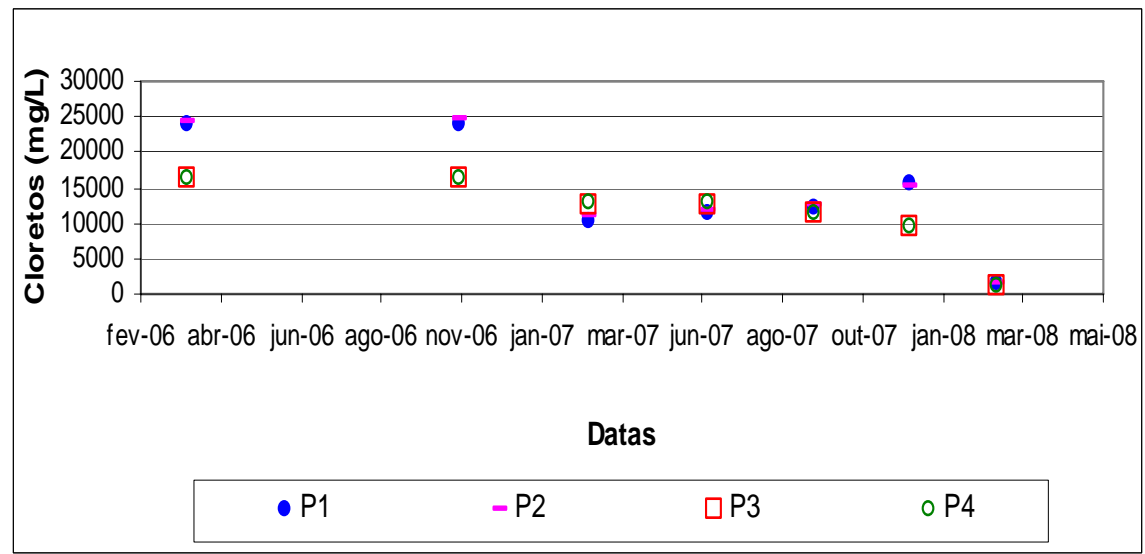

Figura 12. Variação temporal de Cloretos (mg/L).

De acordo com o monitoramento realizado, a qualidade da água do rio Sanhauá, no trecho considerado, não satisfaz aos padrões estabelecidos na Resolução CONAMA N ${ }^{\circ}$ 357/2005 para água salobra classe 1. Faz-se necessário, portanto, a intervenção do Poder Público para tomar medidas e ações no sentido de que o rio Sanhauá passe a ser definido como de água salobra e classificado como Classe 1 e que apresente a qualidade requerida da classe da qual seus usos necessitam.

\section{CONCLUSÃO}

O antigo lixão do Roger continua sendo um dos problemas de degradação e poluição do Rio Sanhauá, mas é preciso atentar que as ações antrópicas principalmente na área do manguezal e na porção estuarina do rio como recreação, navegação, pesca, captura e coleta de mariscos ou crustáceos, lançamento de esgoto doméstico, despejos de resíduos sólidos e uso domiciliar são conflitantes entre si e contribuem para a poluição do rio.

Segundo os usos das águas verificados no rio Sanhauá, sua salinidade e a Resolução CONAMA No 357/2005, o enquadramento desse rio seria de água salobra de Classe 1 . Porém, de acordo com o monitoramento realizado nos pontos P1, P2, P3 e P4, verificou-se que a qualidade da água não satisfaz os padrões de qualidade estabelecidos na referida Resolução CONAMA para essa classe. Faz-se necessário, portanto, a adoção de medidas por parte do poder público no sentido de compatibilizar os usos existentes com a qualidade da água do rio ou a revisão do enquadramento do corpo aquático em benefício da saúde da população local. 


\section{REFERÊNCIAS}

AMERICAN PUBLIC HEALTH ASSOCIATION (APHA). Standard methods for the examination of water and wastewater. 20. ed. New York: Public Health Association, 1998.

BASSOI, L. J.; GUAZELLI, M. R. Controle Ambiental da água. In: PHILIPPI Jr, A.; ROMÉRO, M. de A.; BRUNA, G. C. Curso de gestão ambiental. Barueri: Manole, 2004. p. 53-99.

BRASIL. Lei $\mathrm{n}^{\circ}$ 6938, de 31 de agosto de 1981. Dispõe sobre a Política Nacional do Meio Ambiente, seus fins e mecanismos de formulação e aplicação, e dá outras providências. Diário Oficial [da] República Federativa do Brasil. Brasília, 02 set. 1981.

BRASIL. Lei n. 9433, de 08 de janeiro de 1997. Institui a Política Nacional de Recursos Hídricos, cria o Sistema Nacional de Gerenciamento de Recursos Hídricos, regulamenta o inciso XIX do art. 21 da Constituição Federal, e altera o art. $1^{\circ}$ da Lei $n^{\circ} 8.001$, de 13 de março de 1990, que modificou a Lei ${ }^{\circ}$ 7.990, de 28 de dezembro de 1989. Diário Oficial [da] República Federativa do Brasil. Brasília, 09 jan. 1997.

BRASIL. Resolução CONAMA N 20, de 18 de junho de 1986. Dispõe sobre a classificação dos corpos de água e diretrizes ambientais para o seu enquadramento, bem como estabelece as condições e padrões de lançamento de efluentes, e dá outras providências. Diário Oficial [da] República Federativa do Brasil. Brasília, 30 julho 1986.

BRASIL. Resolução CNRH n¹2, de 19 de julho de 2000a. Dispõe sobre procedimentos para enquadramentos dos corpos aquáticos. Diário Oficial [da] República Federativa do Brasil. Brasília, 20 julho de 2000.

BRASIL. Resolução CONAMA n 274, de 29 de novembro de 2000b. Revisa os critérios de balneabilidade em águas brasileiras. Disponível em: <http://www.mma.gov.br>. Acesso em: 15 jun. 2007.

BRASIL. Resolução CONAMA $\mathbf{n}^{0}$ 357, de 17 de março de 2005. Dispõe sobre a classificação dos corpos de água e diretrizes ambientais para o seu enquadramento, bem como estabelece as condições e padrões de lançamento de efluentes, e dá outras providências. Disponível em: <http://www.mma.gov.br>. Acesso em: 15 jun. 2007.

CAMERON, W. M.; PRITCHARD, D. W. Estuaries. In: The sea - 2. London: WileyInterscience, 1963. . p. 306-324.

DIAS, I. C. S. Estudo da viabilidade técnica, econômica e social do aproveitamento de água de chuva em residência na cidade de João Pessoa. 2007. 116f. Dissertação (Mestrado em Engenharia Urbana) - Universidade Federal da Paraíba, João Pessoa, 2007.

EMLUR. Cadastro dos catadores do Lixão do Roger. João Pessoa: EMLUR, 2003.

INSTITUTO BRASILEIRO GEOGRAFIA E ESTATÍSTICA - IBGE. Pesquisa nacional de saneamento básico. Rio de Janeiro: IBGE, 2000.

INTERSAT. Imagem Landsat7/ETM ${ }^{+}$em 04/08/2001. 2001. Disponível em: <www.intersat.com.br>. Acesso em: 15 jul. 2007.

MARTÍNEZ, S. G.; SOTO, C. A. V. Tratamiento de los lixiviados de un vertedero en un sistema de lodos activados. In: CONGRESO INTERAMERICANO DE INGENIERIA 
SANITARIA Y AMBIENTAL, 27., Porto Alegre, 2000. Anais... Porto Alegre: AIDIS, 2000.

PESSIN, N.; BRUSTOLIN, I.; FINKLER, R. Determinação da eficiência de tratabilidade de reatores biológicos para atenuação de carga orgânica presente no chorume proveniente de aterros sanitários. In: SIMPÓSIO LUSO-BRASILEIRO DE ENGENHARIA SANITÁRIA E AMBIENTAL, 9., Porto Seguro, 2000. Anais... Porto Seguro: Associação Brasileira de Engenharia Sanitária e Ambiental, 2000. p 1496-1503.

QUEIRÓZ, S. M. P. Avaliação de Impactos Ambientais: Conceitos, Definições e Objetivos. In: JUCHEM, P. A. (Coord.). Manual de avaliação de impactos ambientais. Curitiba: SUREHMA/GTZ, 1993. p. 1-11.

RUSSO, M. A. T.; FERREIRA, M.; VIEIRA, C. Caracterização de aterros sanitários de alta compactação. In: SIMPÓSIO LUSO-BRASILEIRO DE ENGENHARIA SANITÁRIA E AMBIENTAL, 9., Porto Seguro, 2000. Anais... Porto Seguro: Associação Brasileira de Engenharia Sanitária e Ambiental, 2000. p 1789-1798.

SEGATO, L. M.; DA SILVA, C. L. Caracterização do chorume do aterro sanitário de Bauru. In: CONGRESSO INTERAMERICANO DE INGENIERIA SANITARIA Y AMBIENTAL, 27., Porto Alegre, 2000. Anais... Porto Alegre: AIDIS, 2000.

SHIKLOMANOV, A. World water resources and their use. UNESCO. 1999. Disponível em: $\quad<$ http://webworld.unesco.org/water/ihp/db/shiklomanov/ summary/html/sum_tab8.html>. Acesso em: 28 jan. 2008.

SOARES, P. F.; LISOT, A. Manual de projeto e análise de desempenho de redes de monitoramento da qualidade da água. Brasília: ANA, 2007.

SUPERINTENDÊNCIA DE ADMINISTRAÇÃO DO MEIO AMBIENTE - SUDEMA. Sistema Estadual de Licenciamento de atividades poluidoras - SELAP. DZS 205: Enquadramento dos corpos d’águas da bacia hidrográfica do rio Paraíba. . João Pessoa: SUDEMA, 1988.

VASCONCELOS, I. C. D.; ATHAYDE JÚNIOR, G. B.; GADELHA, C. L. M.; SANTOS, A. B. Água e poluição. In: ATHAYDE JÚNIOR, G. B.; Santos, A. B. Qualidade da água e controle da poluição. Salvador: Secretaria Nacional de Saneamento Ambiental/RECESA, 2008. 